\title{
Assessing Change in Tobacco Visibility at Point-of-Sale Following a Display Ban
}

\author{
Douglas Eadie, BA Hons \\ Catherine S. Best, BSc, PhD \\ Martine Stead, BA Hons \\ Anne Marie MacKintosh, BSc Hons \\ Nathan Critchlow, BSc, MSc, PhD \\ Richard Purves, BSc, MSc, PhD
}

\author{
Jamie R. Pearce, BSc, MSc, PhD \\ Dorothy B. Currie, BSc Hons, MSc \\ Gozde Ozakinci, PhD, CPsychol \\ Amanda Amos, MSc, PhD \\ Andy S. MacGregor, MBChB, MSc \\ Sally Haw, BSc Hons, Hon MFPH
}

Objectives: In this paper, we describe a point-of-sale (POS) tobacco visibility tool and examine its utility for assessing changes in visibility following legislation banning tobacco displays. Methods: An observational tool was developed as part of DISPLAY, a multimodal, longitudinal study evaluating the impact of the tobacco POS display ban in Scotland. Measures were taken of product and storage unit visibility, over 5 years, pre- and post-implementation in all retail outlets selling tobacco in 4 contrasting study areas $(N=103)$. Results: Data generated by the visibility tool illustrated that whereas the display ban had reduced product visibility, it had little impact on reducing visibility of tobacco storage units. However, it did narrow the inequality gap in storage visibility. It also found some shop types reduced product visibility before legally required to do so. Conclusions: The DISPLAY visibility tool provides a reliable method for measuring visibility of tobacco displays before and after implementation of POS legislation. Tobacco product visibility reduced as expected following implementation of the legislation, but storage unit visibility persisted, providing residual cues of tobacco availability which may confound the effects of the legislation. The DISPLAY tool has the potential to be utilized in countries planning POS display bans.

Key words: tobacco marketing; point-of-sale; display ban; retail audit; measuring visibility

Tob Regul Sci. ${ }^{\mathrm{TM}}$ 2018;4(3):10-28

DOI: https://doi.org/10.18001/TRS.4.3.2

$\mathrm{P}$ oint-of-sale (POS) tobacco displays are a key vector of tobacco marketing in many countries, and at time of writing only 8 countries (Croatia, Finland, Russia, Iceland, Ireland, Norway, Ukraine and the United Kingdom [UK]) out of 44 European countries have legislation prohibiting POS displays, although several including the Netherlands are currently debating such restric- tions. For any country or jurisdiction that plans to implement a ban on POS product displays, it is important to have appropriate research tools which are capable of accurately measuring how the ban affects POS tobacco visibility. Given that there is often socio-economic patterning in tobacco retail distribution and associated exposure, ${ }^{1}$ and that tobacco marketing differs between different types of

Douglas Eadie, Research Fellow, Institute for Social Marketing, University of Stirling, Stirling, Scotland. Catherine S. Best, Lecturer Statistician, Faculty of Health Sciences and Sport, University of Stirling, Stirling, Scotland. Martine Stead, Deputy Director, Institute for Social Marketing, University of Stirling, Stirling, Scotland. Anne Marie MacKintosh, Research Fellow, Institute for Social Marketing, University of Stirling, Stirling, Scotland. Nathan Critchlow, Research Assistant, Institute for Social Marketing, University of Stirling, Stirling, Scotland. Richard Purves, Research Fellow, Institute for Social Marketing, University of Stirling, Stirling, Scotland. Jamie R. Pearce, Professor, Centre for Research on Environment, Society \& Health, School of GeoSciences, University of Edinburgh, Edinburgh, Scotland. Dorothy B. Currie, Senior Statistician, School of Medicine, Population and Behavioural Science Division, Child and Adolescent Health Research Unit, University of St Andrews, St Andrews, Scotland. Gozde Ozakinci, Senior Lecturer, School of Medicine, Population and Behavioural Sciences Division, Center for Higher Education Research, University of St Andrews, St Andrews, Scotland. Amanda Amos, Professor, Usher Institute of Population Health Sciences and Informatics, University of Edinburgh, Edinburgh, Scotland. Andy S. MacGregor, Head of Policy Research (ScotCen), ScotCen Social Research, Edinburgh, Scotland. Sally Haw, Professor, Faculty of Health Sciences and Sport, University of Stirling, Stirling, Scotland.

Correspondence Mr Eadie; douglas.eadie@stir.ac.uk 
Figure 1

Legislative Context

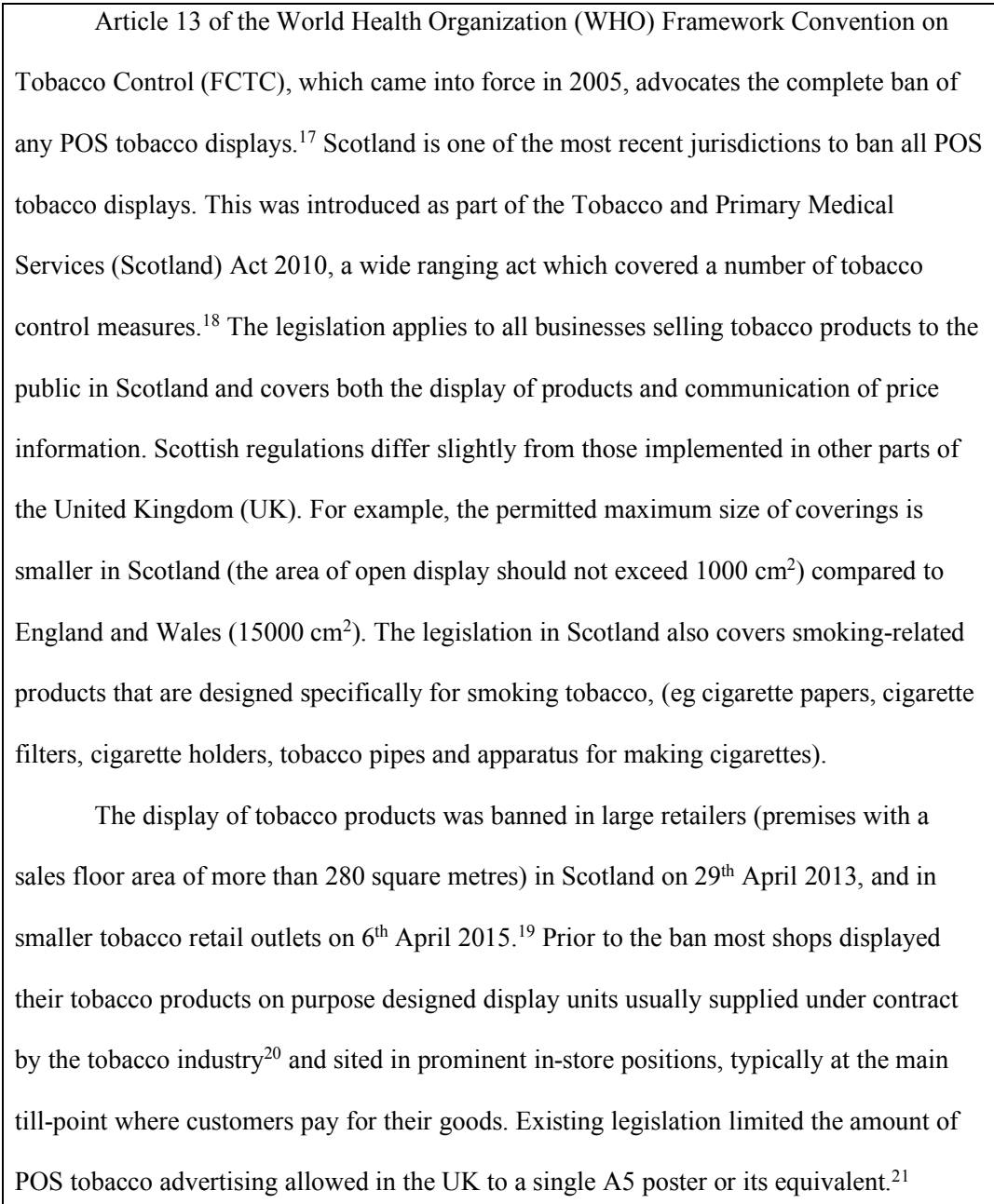

retail outlet, ${ }^{2,3}$ there is also a need to assess whether visibility varies by key variables such as shop type and community characteristics.

This paper describes the development of a tobacco visibility tool and examines its utility for monitoring changes in POS tobacco visibility following the implementation of legislation banning POS tobacco displays in Scotland. The display ban in Scotland formed part of a range of tobacco control measures passed by the Scottish Government in 2010 and was implemented in 2 stages; all large retailers were required to remove displays of tobacco by April 2013 and all small shops by April 2015 (Figure 1). Retailers were required to convert open display units into covered storage units or to store tobacco products out of sight. Figure 2 illustrates the transition from product display gantry to covered storage unit in a small retailer. The visibility tool was designed to measure visibility of tobacco in all fixed retail outlets selling tobacco before, during and following the implementation of the POS legislation in Scotland. The tool was developed and implemented as part of DISPLAY, ${ }^{4}$ a 5 -year multimodal, before and after study designed to evaluate the effect of the Scottish legislation on young people's exposure to tobacco and their smoking attitudes and behavior. ${ }^{5-8}$ Prior to the legislation nearly all branded tobacco advertising had been banned 


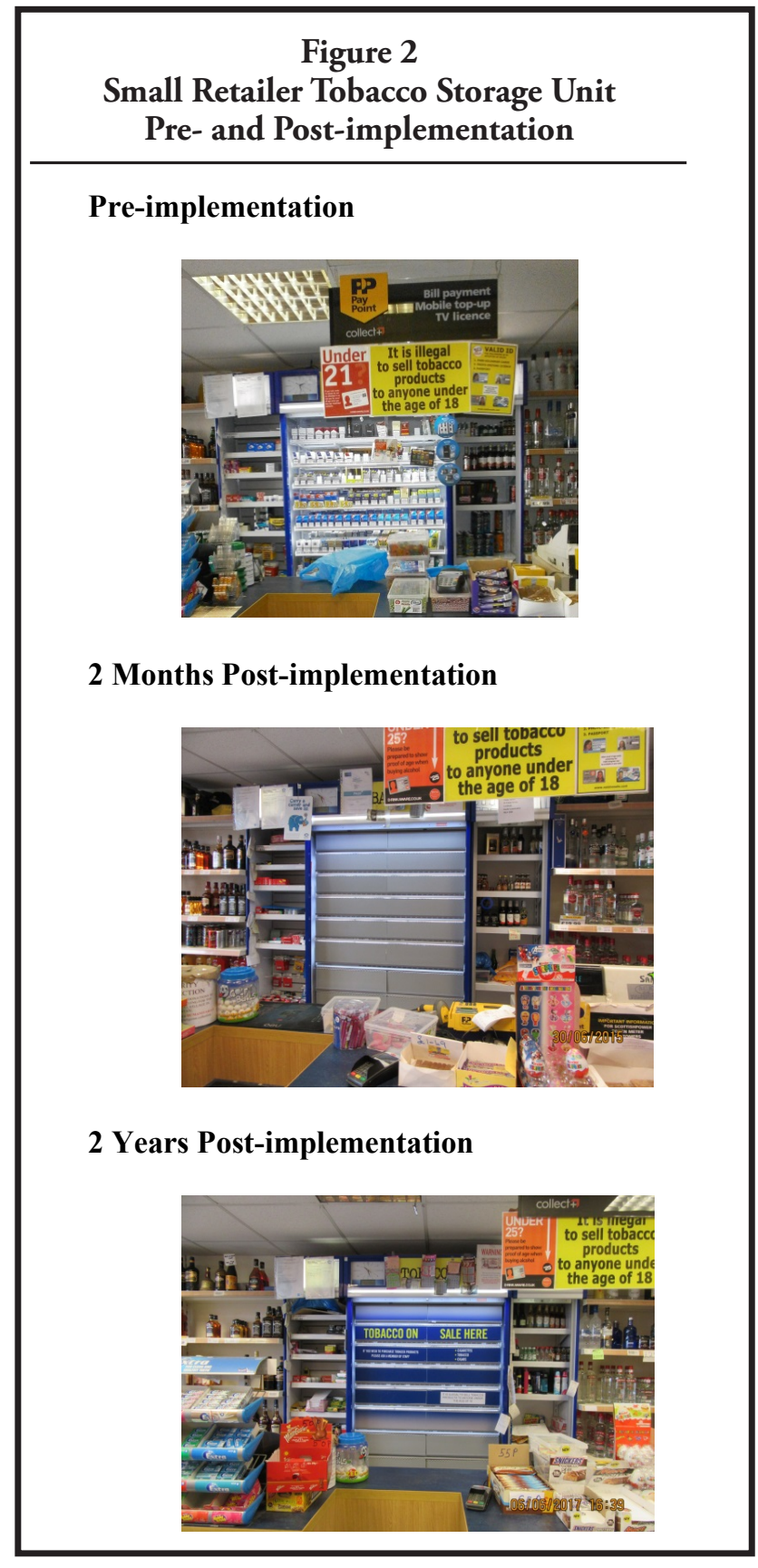

from shop interiors and exteriors in Scotland.

There are several existing tools for measuring tobacco advertising in stores, such as ImpacTeen ${ }^{9,10}$ and Operation Storefront, ${ }^{11}$ but these are of limited value in a context where little POS advertising remains, as was the case in Scotland. Various studies have also examined POS tobacco marketing, ${ }^{12}$ culminating in efforts to develop standardized tools, most notably the Standardized Tobacco Assessment for Retail Settings (STARS). ${ }^{13}$ STARS was developed to assess a wide range of marketing variables, based on the 4Ps of marketing (product availability, placement, promotion, and price), but was not intended to provide detailed measurements of product display and storage unit visibility. Other protocols developed to measure tobacco marketing in the retail environment also fail to capture all the display characteristics relevant to measuring visibility, ${ }^{14,15}$ such as the proximity of customer traffic flows to tobacco displays within the store.

A key limitation of existing tools is that they do not capture the 2 main dimensions of POS tobacco visibility, ie, visibility of tobacco products (which forms the main focus of legislation designed to reduce POS tobacco exposure) and visibility of tobacco storage units (which are often neglected by legislation requiring products to be covered up at POS). Both dimensions are important. Even if tobacco products are covered entirely at POS, prominently positioned storage units carrying generic tobacco signage can act as powerful cues indicating tobacco is for sale. Such cues potentially act as a vector for promoting the continued availability of tobacco products that may encourage young people to start smoking and undermine cessation efforts. ${ }^{16}$

In the absence of an appropriate and comprehensive tool, we developed a dedicated tool to assess these 2 dimensions of POS tobacco visibility. The data were used to generate visibility scores for each dimension for individual retail outlets annually over 5 years from February 2013 to February 2017 to represent time-points before, during, and after implementation of the Scottish display ban.

\section{METHODS}

\section{Study Design}

The DISPLAY study was a multi-modal longitudinal study conducted in 4 study areas in Scotland to assess the impact of the POS tobacco display ban. ${ }^{4}$ Study areas were defined by the catchment area of the secondary school serving the adjacent community, which is the bounded geographic area in which the majority of pupils attending the study schools are resident. Data were collected annually by a range of methods including annual retail mapping, discreet retail audits, secondary school surveys and focus group interviews conducted in each of the 4 study areas between 2013 and 2017. The visibility tool described in this paper is based on 


\begin{tabular}{|c|c|c|c|c|}
\hline \multicolumn{5}{|c|}{$\begin{array}{c}\text { Table } 1 \\
\text { Study Area Characteristics }\end{array}$} \\
\hline \multirow[b]{2}{*}{ Variable } & \multicolumn{4}{|c|}{ Area } \\
\hline & 1 & 2 & 3 & 4 \\
\hline Urban Rural 6-fold Indicator Used by Scottish Government & Other urban & Urban & Urban & $\begin{array}{l}\text { Accessible } \\
\text { small town }\end{array}$ \\
\hline Socio-economic Deprivation & $\begin{array}{l}\text { High } \\
\text { deprivation }\end{array}$ & $\begin{array}{l}\text { High } \\
\text { deprivation }\end{array}$ & $\begin{array}{l}\text { Med/Low } \\
\text { deprivation }\end{array}$ & $\begin{array}{l}\text { Med/Low } \\
\text { deprivation }\end{array}$ \\
\hline Population 10-19 Years Old in 2013 & 2307 & 4817 & 3427 & 2226 \\
\hline Geographic Area (km2) & 19.06 & 10.00 & 21.17 & 910.57 \\
\hline
\end{tabular}

data collected by the discreet audits of all fixed retail outlets that sold tobacco in the 4 study areas. Retail outlets were identified from the Scottish tobacco retailers register (www.tobaccoregisterscotland.org) verified by follow-up field inspections and included supermarkets, small grocery/convenience stores, confectioners/ tobacconists/ newsagents (CTNs), petrol station forecourt stores, off-licenses (liquor stores), and fast-food/ takeaway outlets. The audit data were used to quantify tobacco storage and product visibility at shop level pre- and post-implementation of the ban. ${ }^{22}$

\section{Selection of Study Areas}

Candidate schools were initially identified from those in the central belt of Scotland that had a school enrollment of over 1000 (representing 46\% of schools), were non-denominational, and had an ethnic minority population of less than $10 \%$. An upper limit was placed on schools' ethnic minority population, as in Scotland they represent only $4 \%$ of the total Scottish population. ${ }^{23}$ Schools were then classified by level of social deprivation using the Scottish Index of Multiple Deprivation (SIMD). ${ }^{24}$ The estimate was based on the mean (population-weighted) of the deprivation scores for the data zones (a small-area statistical geography) that fell within the school catchment areas. They were also classified by level of urbanization using the Scottish Government Urban/Rural Classification which combines measures of population and accessibility $^{25}$ to give 6 categories of urbanization - large urban, other urban, accessible small town, remote small town, accessible rural areas and remote rural areas. The final selection of schools rep- resented 2 levels of deprivation (high vs medium to low) and 2 levels of urbanization (large urban vs other urban/small town). Mean SIMD scores for the selected communities ranged from 11.6 to 32.3 (the mean raw SIMD score for all data zones in Scotland is 21.7) and included 2 communities classified as 'large urban' areas (class 1) and one each as 'other urban' and 'accessible small town' areas (class 3). Data indicate that approximately $82 \%$ of pupils in Scotland attend schools located in these classes of area. The characteristics of the 4 study areas are described below (Table 1).

\section{Retail Audit Method}

All tobacco retail outlets in the 4 study areas were visited annually every February/March between 2013 and 2017. These visits took place just before the introduction of the ban in large stores (2013), at follow-up 10 months after the large store ban (2014), just before the introduction of the ban in smaller shops (2015), and at follow-up 10 months (2016) and 22 months (2017) after the smaller shop ban. Two additional visits were conducted post implementation of the display ban in large and smaller shops in May 2015 and April 2016 to assess short term compliance. ${ }^{16}$ Further details of the retail audits and how shops were identified are given in previous publications. ${ }^{8,22}$

Observers worked in pairs to conduct the audits which were undertaken discreetly without retailer's being aware. Data collection was facilitated by a token purchase made in each retail outlet to gain access to the tobacco counter, and the use of memory aids and devices, such as mobile phones to record key numeric data (eg, number of stor- 
age unit shelves). Data were then transferred onto a structured paper pro forma away from the retail sites immediately following each observation, with observers comparing notes to verify key characteristics. Emergent inconsistencies or gaps were addressed by an immediate follow-up visit to the study outlet. Two researchers with experience of observation methods in commercial settings undertook the pilot work and developed the measurement tool. The same 2 researchers also undertook the data collection across all waves supported by 3 other researchers. All researchers were full time members of research staff within the academic team responsible for this element of the DISPLAY study.

\section{Visibility Tool Development}

The development of the DISPLAY visibility tool involved a review of existing literature and in-store pilot observations. Whereas previous studies have developed tools for auditing tobacco retail environments, ${ }^{12,14}$ many are designed to measure features that are not relevant in Scottish stores, such as price promotions, self-service counters and advertising. Measures identified in the literature review which were relevant to the current study included: the presence of a display unit or 'power wall' of visible tobacco products, ${ }^{26}$ the position of tobacco products in relation to the till, ${ }^{15}$ and signage indicating that tobacco products are for sale. ${ }^{14,26}$ Although existing and previously used audits often include measures of the volume and size of tobacco advertising in stores, ${ }^{13,27,28}$ we did not find any suitable audit tools which measured the size and positioning of product display units. This is important, particularly in a context where in-store advertising has been restricted, as the display unit itself can be seen to function as a form of tobacco advertising. ${ }^{29}$

Following the review of previous research, we conducted a series of pilot observations in stores not included in the main DISPLAY study to devise ways of measuring those aspects of tobacco visibility relevant to the Scottish retail context. A key consideration was that data should be able to be collected discreetly to avoid the risk of measurement influencing retailer behavior and compliance with the ban. In addition, the tool had to be capable of assessing visibility in the main types of shop where tobacco is sold in Scotland, namely; supermarkets, small grocery/convenience stores, con- fectioners/tobacconists/newsagents (CTNs), petrol station forecourt stores, off-licenses (liquor stores), and fast-food/takeaway outlets.

Development of the tool was an iterative process, involving a number of repeat visits to pilot shops to revise and refine the visibility measures and recording techniques. Modifications and updates were also made to the tool post-implementation of the legislation to take into account changes to the retail environment and the way retailers chose to adapt to the product display ban, such as where and how they chose to store their tobacco stock. These updates were supported by interviews and field visits with a retailer panel $(\mathrm{N}=24)$ who were recruited from matching areas outside the 4 study communities to monitor changes in the way retailers adapted to the display ban. ${ }^{4,5}$

As well as developing the visibility tool, the pilot observations and retailer panel were also used to identify and develop tools for measuring several other tobacco marketing features associated with tobacco displays, such as display unit types, price marking and proximity of displays to products with appeal to children. Results relating to these and other features are reported elsewhere. ${ }^{6,22}$

\section{Measurement of Visibility: Visibility of Tobacco Products}

The purpose of the POS display legislation was to reduce the visibility of product displays, the main vector of tobacco marketing in the Scottish retail environment at that time,$^{20-30}$ by requiring that all tobacco products were either fully covered or removed entirely from customer sight by being placed elsewhere (eg, under-the-counter). We used a 5-point categorical scale to measure visibility of tobacco products, where 4 = full visibility of products and $0=$ zero visibility of products. It would be expected that, following implementation of the legislation, retail outlets that had previously scored 4 for having all of their tobacco products on open display would receive a lower score, reflecting their compliance with the legislation. A score of 3 would indicate that some products remained on permanent display, for example as a result of a poorly designed or broken storage unit. A score of 2 would indicate that some products were on temporary display, for example as a result of a sales assistant leaving some access doors or covers open. A score 
of 1 would indicate that all tobacco products were completely covered up in a storage unit visible to the public and products were only fleetingly visible when access doors were opened to retrieve products for purchase, and a score of zero would indicate no product visibility (ie, tobacco products are stored under the counter or elsewhere out of customer sight and visibility is restricted to only those products purchased as they are handed over to the customer during the sales transaction).

\section{Measurement of Visibility: Visibility of Tobacco Storage Units}

Reflecting the fact that tobacco storage units are positioned to attract customer attention within the shop environment, 4 measures were developed to assess storage unit characteristics:

- Visibility of tobacco storage units at point of purchase.

- Proximity of the tobacco sales counter to customer traffic flows through the store.

- Size of tobacco storage units.

- Conspicuousness of tobacco storage units within the surrounding retail environment.

Whereas all shops in Scotland sold tobacco from internal tobacco counters, pilot observations found that in some shops, tobacco storage units were visible from the exterior of stores through windows and doorways. Consequently, a fifth measure was included to assess external visibility of tobacco storage units. The grading scales developed to assess all 5 visibility characteristics are described in more detail below and illustrated in Appendix A.

Visibility of tobacco storage units at point of purchase. Five indicators were used to assess the visibility of tobacco storage units at point of purchase - whether the storage unit was: (1) behind the service counter; (2) at customer eye-level; (3) within arms-reach of the shop assistant; (4) parallel to the counter; and (5) availability of tobacco was clearly denoted by customer facing generic tobacco signage (eg, the words 'tobacco' or 'cigarettes' printed on the storage unit) or the existence of tobacco products on permanent display. Each item was scored on a binary scale $(1=$ Yes, $0=\mathrm{No})$ and values for all 5 items were then aggregated to generate an overall score for visibility from sales counter, with positive values for all 5 indicators achieving a score of 5 , and the presence of no indicators a score of zero.

\section{Proximity of tobacco sales counter to customer} traffic. This measure assessed the proximity of the tobacco sales counter to routine customer traffic through the store. Pilot observations found 3 main features of shop design affecting proximity: (1) type of sales counter where customers were required to purchase their tobacco; (2) level of customer traffic passing the tobacco sales counter, and (3) proximity of the tobacco sales counter to other sales counters within the store. These 3 features were rank-ordered to devise a 5-point categorical scale ranging from 5 , high proximity to customer traffic (customers purchased their tobacco at the same sales counter as other grocery items) to 1 low proximity to customer traffic (customers purchased their tobacco from a separate tobacco kiosk, with low levels of passing customer traffic and low visibility to other sales counters within the store). A detailed description of the scale is provided in Appendix A.

Size of storage unit. It was not possible to measure the physical dimensions of the tobacco storage units explicitly in each retail outlet due to the discreet nature of the observations. To overcome this, we used 2 measures to assess size of storage unit, preimplementation we took a count of tobacco packs on display and post-implementation we counted storage unit door covers. At baseline, we estimated the height and width of tobacco storage units based on mean values for tobacco shelf height and pack width calculated from physical measurements taken in a sub-sample of the pilot shops. These mean values were then used to calculate the total display area (height $\mathrm{x}$ width) in shops undergoing discreet observation, by counting the number of shelves and number of forward facing products on display. Mean height and width values were applied to create an estimate of the total storage area occupied by tobacco products. The observed storage areas were divided into quintiles with adjustment to make category sizes consistent. This resulted in a 5-point graduated scale based on distribution, ranging from 5 , an area of $2.8 \mathrm{~m}^{2}$ or larger, to 1 , an area of 1.29 $\mathrm{m}^{2}$ or smaller. Where products were stored out of sight in a concealed storage unit, for example under the counter, size was assigned a zero value.

At follow-up, we found that stores had either 
modified their existing storage units by attaching doors rather than installing new units, or in a few cases, had removed products to under-the-counter in order to conceal products. ${ }^{6}$ This was corroborated by findings from our retailer panel. As a result, where doors had been attached to the original storage unit, data collected at baseline provided the most accurate estimate of storage unit size and was applied to the subsequent waves of data. For new shops, in which estimated measurements of storage units were not determined at baseline $(\mathrm{N}=4)$, the value from a shop with an identical/near identical storage unit (based on type of storage unit and number of door columns and rows) was applied.

Storage unit conspicuousness. Observations indicated that the ability for tobacco storage units to stand out within the retail setting was not simply dependent on size (which emerged from the pilot observations as the most striking design feature), but also on a range of other potential features not legislated for, including use of lighting, color, shop layout and signage. To assess the impact of these other factors, observers were prompted to make a subjective assessment of tobacco unit visibility by asking them to: (1) take into account its ability to stand out within the shop setting; and (2) make the assessment as they walked towards the service counter using a 5 -point scale from $5=$ high to $1=$ low. Where products were stored out of sight in a concealed storage unit, conspicuousness was assigned a zero value.

External visibility. Assessment of external visibility was made from 2 vantage points: (1) the pedestrian footway in front of the shop; and (2) the shop's main doorway. Visibility for each was scored on a binary scale $(1=$ Yes; $0=\mathrm{No})$ and values added together to generate a score for external visibility [range 0-2].

\section{Calculating Storage Unit Visibility}

Storage visibility score was computed for each retail outlet based on measures of in-store visibility and external visibility of storage units. Scores for the in-store visibility characteristics (visibility from the sales counter, proximity to customer traffic, storage unit size and conspicuousness) (each 0-5) and the external visibility score (range 0 - 2) were aggregated giving a maximum possible storage unit visibility score of $22(5+5+5+5+2)$. A proportionately lower value was attached to external vis- ibility compared to internal visibility reflecting the fact that all tobacco transactions take place within the store at a shop counter and all storage units are positioned to attract customers at the shop till point. Consequently, any exposure to storage units from passers-by outside of premises, through shop windows and doorways, is only fleeting. Appendix A describes all of the measures used to assess product and storage unit visibility.

\section{Inter-rater Reliability}

To test reliability, 2 researchers conducted independent visits with a cross-section of retailers in one of the 4 study areas $(\mathrm{N}=13 ; 14 \%$ of the total sample). Both visits were undertaken at the same time point, one immediately after the other, to minimise the risk of extraneous changes in the store (eg, store layout altered) influencing scoring. To establish inter-rater reliability, percentage agreements on 12 separate items were compared and Cohen's Kappa $(k)$ used to assess reliability (Appendix B). This included categorical variables (ie, Yes/No response), ordinal scales (Likert scales) and continuous variables (eg, height and width of tobacco unit). There was considerable agreement across all 12 items, with $100 \%$ agreement [13/13 shops] on 8 items and $92 \%$ agreement [12/13 shops] on 4 items. These estimates exceed the suggested $70 \%$ threshold for acceptable inter-rater agreement using the percentage measure. ${ }^{31}$ The Cohen's $k$ for each item were above the suggested 0.60 threshold for moderate to strong reliability (range: 0.76 $-1.00) .{ }^{32} \mathrm{~A}$ breakdown of agreement by each item is reported in Appendix C.

\section{Data Analysis}

Data analysis was conducted in Stata version 14 (StataCorp). Retail outlets were coded by study area and were assigned SIMD deprivation quintile scores ${ }^{33}$ according to the data zone (small area geography) in which they were located. Changes in visibility scores over time were examined by study area and SIMD-quintile of socio-economic deprivation. ${ }^{20}$ Changes in the visibility scores were examined graphically through plots of means and their associated standard errors. To test whether observed differences remained significant after adjustment for other factors (eg, store type) we conducted multivariable regression analyses for 


\begin{tabular}{|c|c|c|c|c|}
\hline \multicolumn{5}{|c|}{$\begin{array}{c}\text { Table } 2 \\
\text { Retail Outlets by Study Area }\end{array}$} \\
\hline \multirow[b]{2}{*}{ Outlets } & \multicolumn{4}{|c|}{ Area } \\
\hline & 1 & 2 & 3 & 4 \\
\hline Total Number of Tobacco Retail Outlets 2013 & 18 & 40 & 19 & 19 \\
\hline Total Number of Tobacco Retail Outlets 2017 & 18 & 38 & 20 & 17 \\
\hline Number of Supermarkets 2013 & 3 & 1 & 2 & 3 \\
\hline Number Off-licenses 2013 & 1 & 1 & 1 & 1 \\
\hline Number of Confectioner, Tobacconist and Newsagents 2013 & 2 & 8 & 4 & 2 \\
\hline Number of Grocers / Convenience Stores 2013 & 10 & 28 & 7 & 9 \\
\hline Number of Petrol Station Shops / 'Forecourt Garages'; 2013 & 2 & 2 & 3 & 3 \\
\hline Number of Fast Food / Other Catering Outlets 2013 & 0 & 0 & 2 & 1 \\
\hline
\end{tabular}

the continuous measures and used alternative nonparametric methods for ordinal outcomes.

\section{RESULTS}

The number of retail outlets within the 4 study areas was very stable between 2013 and 2017 with a maximum of one net change in the number of outlets over the study period. In 2013 and 2014 there were 96 outlets, in 2015 - 94 outlets, 2016 - 95 outlets, and 93 outlets in the final audit in 2017. In light of the overall stability, a breakdown of retail outlet types (supermarket, grocers, petrol station etc) is given only for the baseline year (2013) (Table 2).

\section{Product Visibility}

The mean product visibility score for all outlets $(\mathrm{N}=96)$ before the display ban was $3.96(\mathrm{SD}=$ 0.41 range $0-4)$. After the ban was implemented in supermarkets, the mean product visibility score (for all outlets $\mathrm{N}=94)$ dropped to $3.16(\mathrm{SD}=1.33$ range $0-4)$ and then dropped to $1.13(\mathrm{SD}=0.57$ range 0-3) after the ban was fully implemented in all outlet types $(\mathrm{N}=93)$.

Change in average tobacco product visibility over time by study area. Figure 3 below illustrates the change in average product visibility score over time in each of the 4 study areas. The bars indicate the standard error of the mean.

An ordinal logistic regression indicated that Area
4 (med/low deprivation and accessible small town) was significantly different to Areas 1 and 2 (the high deprivation large urban area and the high deprivation other urban area) in terms of product visibility, Area 4 having overall lower product visibility. Two cross-sectional Mann Whitey $\mathrm{U}$ tests indicate that Area 4 tended to have lower product visibility before the ban $(\mathrm{z}=2.01 \mathrm{p}=.044)$ and after the ban $(\mathrm{z}=$ $1.99 \mathrm{p}=.047)$ in comparison to the other 3 areas combined. This suggests that outlets in Area 4 had lower product visibility than the other areas and that this difference was not affected by the display ban.

Relationship between retail tobacco product visibility and socio-economic deprivation within the 4 study areas (results not shown). We examined the relationship between area-level deprivation (by SIMD) and retail-level tobacco product visibility. There were no differences in product visibility scores between outlets in high and low deprivation areas before the display ban and no differences in product visibility scores between outlets in high and low deprivation areas after the display ban.

Change in product visibility scores by retail outlet type. It might be expected that, as the POS display legislation was implemented in stages through the introduction of a partial ban in April 2013 (large supermarkets) then extending to a comprehensive ban in April 2015 (large supermarkets and smaller shops), there would be 2 distinct points of change in retail display product visibility. Examining the change in product visibility scores over time 
Figure 3

Change in Mean Product Visibility Score in Each Study Area over Time (All Outlets)

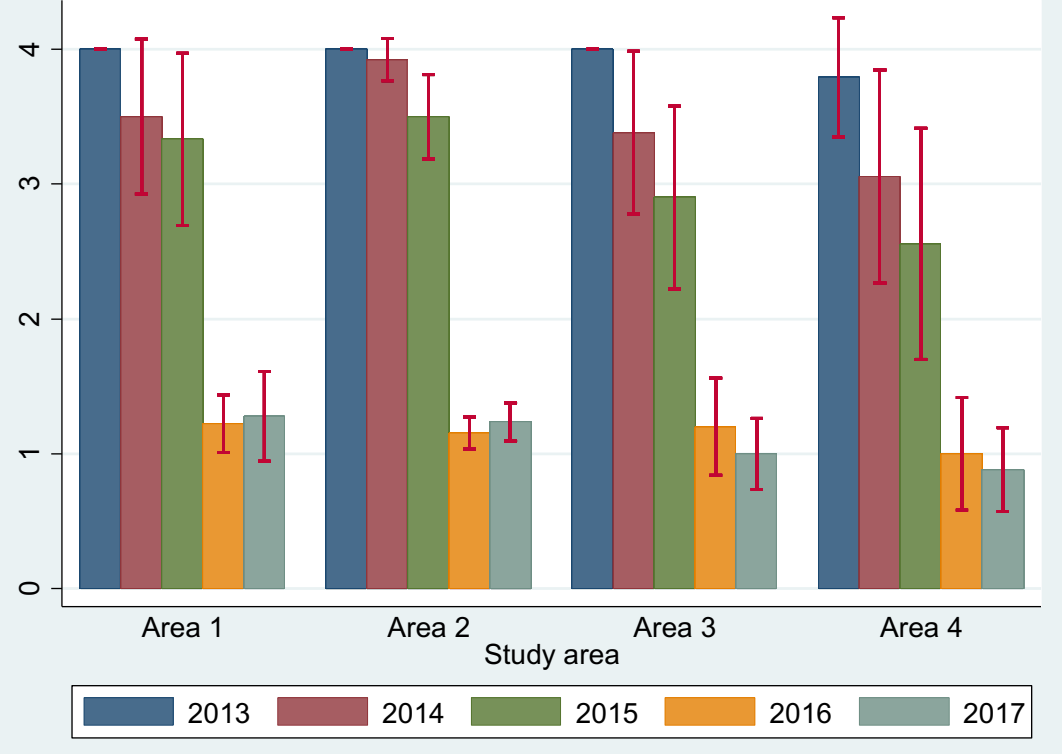

Figure 4

Change in Tobacco Product Visibility Over Time by Store Type

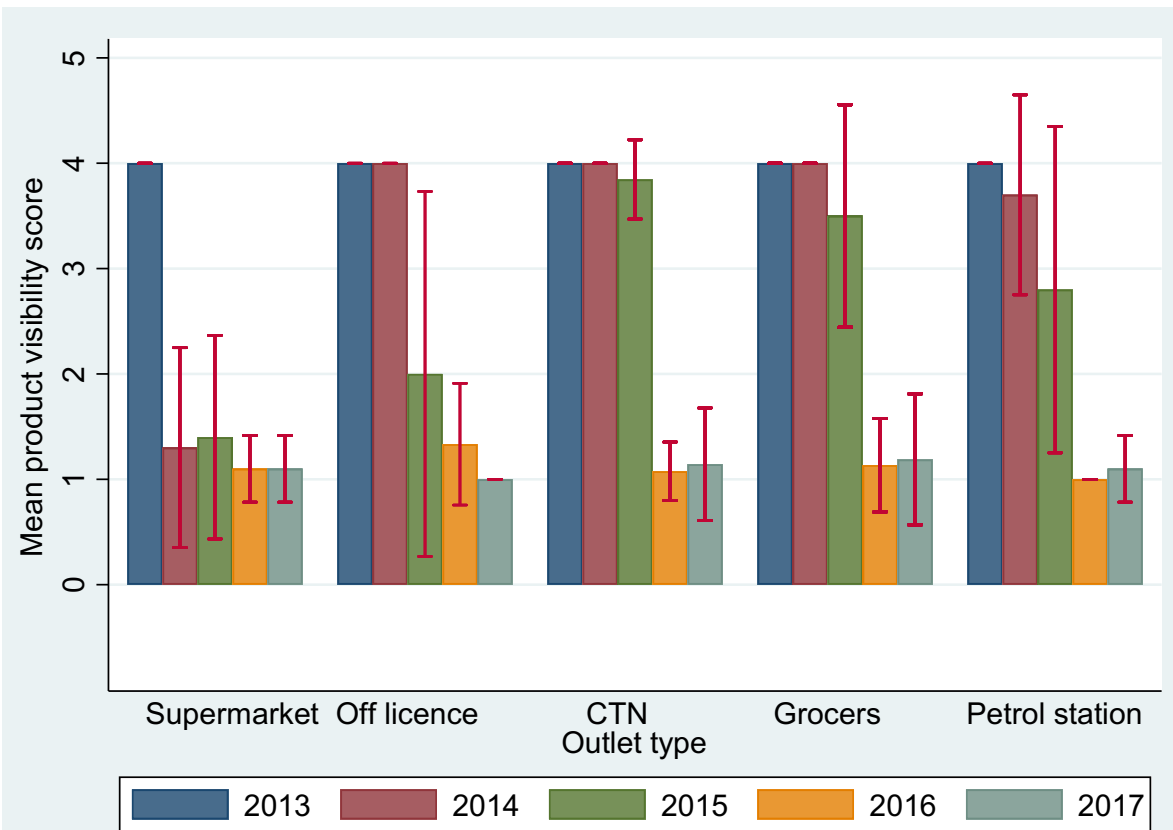

Note.

Standard error of the mean is indicated by capped lines. 
Figure 5

\section{Change in Tobacco Storage Visibility over Time by Study Area (All Oulets)}

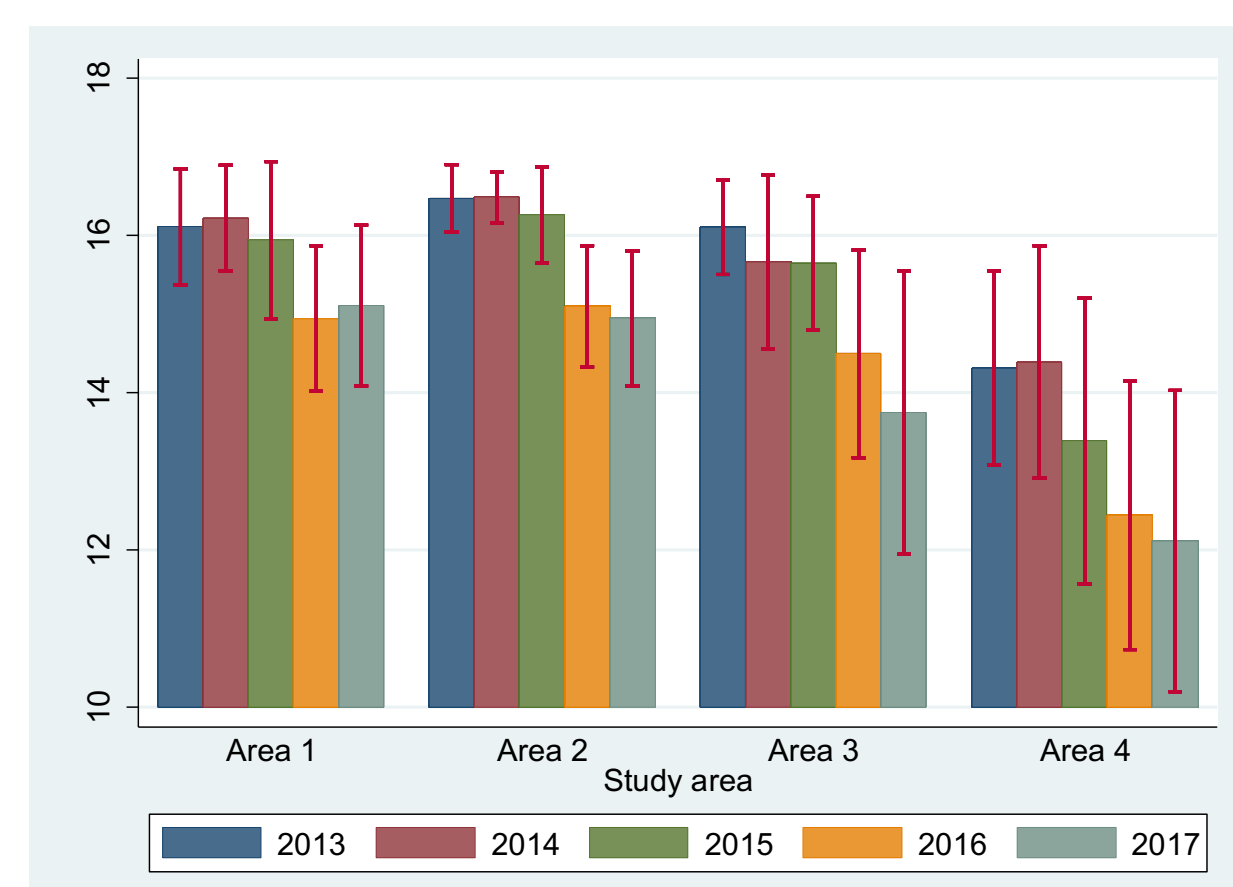

Note.

Standard error of the mean is indicated by capped lines.

by outlet type revealed that, as expected, product visibility in supermarkets did reduce sharply after 2013. However, for other retail outlet types there was a more gradual change, with grocers and petrol stations, in particular, having a wide range of product visibility scores in early 2015 before bans were extended to include smaller outlets. This can be seen in Figure 4 with the wide error bars in 2015 for grocers and petrol stations.

This indicates that some of the grocers and petrol stations adjusted their displays before the ban came into force. Fast food outlets are not shown in the graph as there are too few of these types of outlet for variation to be illustrated in this way.

\section{Storage Unit Visibility}

The mean storage unit visibility score for all outlets $(\mathrm{N}=96)$ before the display ban was 15.91 (SD $=1.82$ range $5-19$ ). After the ban was implemented in supermarkets, the mean storage unit visibility score (for all outlets $\mathrm{N}=94$ ) dropped slightly to
$15.52(\mathrm{SD}=2.52$ range $5-20)$ and then again by another small amount to $14.20(\mathrm{SD}=3.20$ range 5-19) after the ban was fully implemented in all shop types $(\mathrm{N}=93)$. Most of the change in storage unit visibility scores was attributable to reduction in the conspicuousness of storage units, which would appear to indicate that storage units which display tobacco products are more likely to stand out in the shop environment than storage units where products are covered.

Change in average tobacco storage unit visibility over time by study area. Figure 5 above illustrates the change in average storage unit visibility score over time in each of the 4 study areas. (The bars indicate the standard error of the mean.)

Area 4, which was predominantly rural in character (a medium sized market town surrounded by farmland and small villages), and with a more geographically dispersed population, had lower mean storage unit visibility scores per retail outlet than the other areas both before and after the ban. A 
regression of year and area against storage visibility score indicated that Area 4 had significantly lower mean visibility scores than the large urban areas (Area 3 ref Area $4 \beta=1.79 \mathrm{p}=.025$, Area 2 ref Area $4 \beta=2.51 \mathrm{p}=.001)$, and the 'other urban' area (Area 1 ref Area $4 \beta=2.33 \mathrm{p}=.002$ ). Interacting time and area as a predictor had no effect, indicating the display ban did not lessen the difference between Area 4 and the other areas in mean storage unit visibility. This suggests that a POS ban may not eliminate urban/rural differences in retail-level tobacco storage unit visibility.

\section{Relationship between retail tobacco storage} unit visibility and socio-economic deprivation within the 4 study areas. Before and after the ban, retail outlets in more deprived areas had, on average, higher tobacco storage unit visibility scores. The mean tobacco storage unit visibility score before the ban was $16.16(\mathrm{SD}=2.02$ range 5-19) in high deprivation postcodes (SIMD quintiles 1 and 2 ) and 15.54 (SD $=1.43$ range $12-19)$ in low deprivation postcodes (SIMD quintiles 3-5). This difference was found to be significant in a Mann Whitney $U$ test $(\mathrm{z}=-2.35 \mathrm{p}=.02)$. After the ban, the mean storage unit visibility score in high deprivation postcodes was $14.48(\mathrm{SD}=3.12$ range 5-19) and in low deprivation postcodes 13.97 (SD $=3.01$ range $6-18)$. This difference was not statistically significant. We found that the difference between deprived (SIMD quintiles 1 and 2) and less deprived areas (SIMD quintiles 3-5) in terms of tobacco storage unit visibility was diminished by the POS display ban.

Change in storage unit visibility scores by retail outlet type. Changes in storage visibility by retail outlet type over time were examined graphically with reference to the standard errors of the mean scores. There was a small decline in mean storage visibility for most outlet types over the observation waves with the exception of supermarkets (Appendix D).

\section{DISCUSSION}

This DISPLAY visibility tool provides a comprehensive and reliable instrument for measuring tobacco visibility in retail settings and changes in visibility as a result of legislation restricting POS tobacco product displays. Assessment of interrater reliability showed strong agreement. The tool proved feasible to use in a range of retail environments and shop types without noticeable disruption or detection by retailers or customers. We were able to identify changes in tobacco (product and/or storage unit) visibility over time, between retail outlets of different types, and by differences in deprivation. The work reported here augments existing retail audit tools which are designed for environments where advertising is already severely restricted (as was the case in Scotland) or which do not measure features of POS displays in sufficient detail, ${ }^{13-15}$ and has the potential to be utilized in other countries implementing POS display bans.

We found large reductions in visibility of tobacco products after each of the 2 implementation dates for the legislation, indicating that retailers had complied successfully with the ban on tobacco displays. ${ }^{6}$ However, the way that retailers chose to comply was noteworthy. Despite the fact that prior to the ban tobacco products were normally displayed in prime positions, typically behind the main till-point, retailers normally opted to comply by adding covers and doors to existing tobacco storage units rather than by moving tobacco to another part of the store (eg, under the service counter) and reusing the prime display space to promote other goods. Consequently, we found that the visibility of storage units reduced only slightly following implementation. The differences in trends for the 2 scales, product visibility and storage unit visibility, illustrate the importance of measuring these 2 elements of POS tobacco visibility separately. In some studies, POS tobacco product display bans are thought to have only one outcome - the elimination of all tobacco at POS. ${ }^{34}$ However, as we have seen in our study, even when tobacco retailers in Scotland complied with the legislation and covered up their tobacco products, the continued sale of tobacco products from large shuttered storage units with generic tobacco signage or descriptors such as 'tobacco for sale' or 'cigarettes' in large letters meant that tobacco-related cues were still highly visible at POS. Evidence suggests that such cues, even in an otherwise 'dark' market where products are covered up and/or are available only in standardised packs, can still signal tobacco availability and trigger cravings in existing smokers. ${ }^{35}$

The persistent visibility of tobacco as a generic product at POS has important implications. In our theory of change and logic model associated with 
the POS legislation, we hypothesized that the display ban would protect young people from the influences of tobacco advertising and promotions by reducing brand awareness and perceptions of availability, thereby changing smoking attitudes and social norms and ultimately leading to a reduction in smoking incidence and prevalence in young people. ${ }^{4}$ However, the omnipresence of tobacco and its persistent visibility as a generic product has the potential to undermine the impact of POS legislation by reminding young people of tobacco availability. This suggests that, contrary to our proposed model, the display ban may reduce brand awareness but not perceived tobacco availability. Future analyses of our DISPLAY study data will help illuminate the pathways to impact of the Scottish legislation. This will include examination of the retail-level visibility scores for each retail outlet with individual-level measures of residential retail outlet density to assess the relationship between visibility-density and smoking attitudes and behavior. Further research is required in other jurisdictions. In the interim, both countries with legislation and those considering a display ban at POS should consider extending the legislation to regulate the position and prominence of the storage unit itself, or removing the storage unit completely from public view.

Through the development of the DISPLAY visibility tool we have been able to demonstrate that changes in POS tobacco displays did not necessarily occur precisely in line with the timing of the legislation. Many smaller shops decided to change their displays in advance of the implementation date set out in the legislation for smaller store compliance (2015), with some making changes straight after the date set out in the legislation for supermarket compliance (2013). This was probably because such stores were part of a supermarket chain or group and the legislation was implemented at the same time irrespective of store size. Data illustrating precisely when changes occur in response to tobacco control legislation are important for explaining any changes in tobacco-related attitudes and behaviors which are detected in surveys or time series studies.

Analysis of the data generated by the visibility tool by area and shop type, before, during and after a partial and full ban on point of sale product display in Scotland revealed a number of other important findings. Firstly, the mean tobacco storage unit visibility scores for outlets in more deprived postcode areas were higher than those for outlets in less deprived postcode areas. This finding is in line with other studies that have found higher levels of tobacco marketing in more deprived areas. ${ }^{36}$ In our previous work we found that before the ban, storage units for tobacco were larger in newsagents and grocers in more deprived areas than in those in less deprived areas. ${ }^{22}$ The findings reported here confirm and extend this work by employing a more comprehensive measure of visibility. Importantly, this difference was reduced successfully by banning POS tobacco product displays. The differences in retail-level tobacco storage unit visibility between the shops in more and less deprived postcode areas diminished over time, that is to say before and after the POS tobacco display ban. This suggests that POS tobacco display bans have the potential to eliminate differences in tobacco storage unit visibility thus contributing to a reduction in inequalities.

A limitation of the study is its reliance on observer recall and the lack of physical measurement for some aspects of visibility, which created particular challenges when assessing changes in storage unit size following implementation of the display ban. However, we found inter-rater reliability to be very high. Alternative approaches to measuring tobacco visibility could involve overt measurement, conducted with retailer knowledge and consent, such as the use of apps or photography. Combs, Moreland-Russell and Roche ${ }^{37}$ undertook an evaluation of apps suitable for measurement of tobacco product displays, and while some are analytically promising, none were suitable for discreet audit as they required behind-the-counter access. Whereas the use of overt measurement with retailer consent may generate more accurate data, the risk of sampling bias or low response is considerable. For example, Spanopoulos et al ${ }^{38}$ reported that only $56 \%$ of tobacco retailers consented to take part in a study using photography. Our study relied upon adult observers to assess visibility, so measurement is based on an adult perspective (for example, assessment of display units being at eye level). Additional items that reflect a child's perspective may be of value when considering impact on young people, for example, proximity of tobacco displays and storage units to products with youth appeal.

Another limitation of the study is that the tool was designed to assess visibility in a Scottish retail 
context where nearly all branded tobacco advertising had been banned from shop interiors and exteriors ${ }^{21}$ and where tobacco is sold from a wide number of regular retail outlets (in some countries the selling of tobacco is restricted to designated outlets). Similarly, tobacco in Scotland and the rest of the UK is sold from enclosed premises. Sale from high street stalls and kiosks are not a common feature in the UK and automated vending has been outlawed. However, there is scope to adapt the tool to assess the different dimensions of visibility, namely product visibility and visibility of storage arrangements, in other retail environments where tobacco products are displayed and sold outdoors. Our study assessed visibility at fixed retail outlets, and did not include the selling of tobacco from mobile vans which are less common, or from drinking premises licenced to sell alcohol. The illicit tobacco trade, although a source of tobacco in Scotland, was not included as the selling of illicit tobacco is a covert activity and was therefore not considered to significantly contribute to visibility.

\section{IMPLICATIONS FOR TOBACCO REGULATION}

The visibility tool provides a method for assessing the impact of POS legislation in other countries and jurisdictions. Importantly, our data show that POS product display bans do not necessarily remove all cues indicating tobacco availability. In Scotland, legislation banning the display of tobacco products was effective at removing products from public view, but had little influence on where tobacco products were stored and the visibility of tobacco storage units. Methods for assessing visibility need to determine not only whether retailers comply with display legislation, but also which residual tobacco cues remain or are replaced in the retail environment. Regulators in other countries implementing similar bans might usefully consider restricting the size and position of tobacco storage units and use of signage and colour to denote tobacco availability, and banning the use of retailer incentives by tobacco manufactures to retain tobacco in public facing storage units. ${ }^{5}$ Such changes might also be supported by advice to retailers on the commercial opportunities created by the removal of tobacco and how best to maximise the vacated display space.

\section{Conflict of Interest Statement}

The authors have no conflicts of interest.

\section{Human Subjects Statement}

The University of Stirling School of Management Research Ethics Committee approved this study and the use of discreet observation methods.

\section{Acknowledgements}

The research team thanks Dr Mirte Kuipers from the Academic Medical Centre, University of Amsterdam for her advice on the research topic. The study was funded by the NIHR, grant reference10/30000/07.

\section{References}

1. Lee JGL, Henriksen L, Rose SW, et al. A systematic review of neighborhood disparities in point-of-sale tobacco marketing. Am J Public Health. 2015;105(9):e8-18.

2. Feighery EC, Ribisl KM, Schleicher N, et al. Cigarette advertising and promotional strategies in retail outlets: results of a statewide survey in California. Tob Control. 2001;10(2):184-188.

3. Barnoya J, Colditz G, Moreland-Russell S, et al. Prevalence of cigarette advertising and other promotional strategies at the point of sale in St Louis, Missouri: analysis by store type and distance from a school. Prev Chronic Dis. 2014;11:130-150.

4. Haw S, Amos A, Eadie D, et al. Determining the impact of smoking point of sale legislation among youth (Display) study: a protocol for an evaluation of public health policy. BMC Public Health. 2014;14(1):251.

5. Stead M, Eadie D, Purves RI, et al. Tobacco companies' use of retailer incentives after a ban on point-of-sale tobacco displays in Scotland. Tob Control. 2017 Jul 31. pii: tobaccocontrol-2017-053724. doi: 10.1136/tobaccocontrol-2017-053724. [Epub ahead of print] Available at: http://www.ncbi.nlm.nih.gov/pubmed/28760911. Accessed December 12, 2017.

6. Eadie D, Stead M, MacKintosh AM, et al. Are retail outlets complying with national legislation to protect children from exposure to tobacco displays at point of sale? Results from the first compliance study in the UK. PLoS One. 2016;11(3):e0152178.

7. Best C, Haseen F, van der Sluijs W, et al. Relationship between e-cigarette point of sale recall and e-cigarette use in secondary school children: a cross-sectional study. BMC Public Health. 2016;16(1):310.

8. Eadie D, Stead M, MacKintosh AM, et al. E-cigarette marketing in UK stores: an observational audit and retailers' views. BMJ Open. 2015;5(9):e008547.

9. The Robert Wood Johnson Foundation. About Impacteen. Available at: http://impacteen.uic.edu/aboutus. htm. Accessed May 29, 2017.

10. Lovato CY, Hsu HCH, Sabiston CM, et al. Tobacco point-of-purchase marketing in school neighbourhoods 
and school smoking prevalence: a descriptive study. Can J Public Health. 2007;98(4):265-270.

11. Glanz K, Sutton NM, Arriola KRJ. Operation storefront Hawaii: tobacco advertising and promotion in Hawaii stores. J Health Commun. 2006;11(7):699-707.

12. Lee JGL, Henriksen L, Myers AE, et al. A systematic review of store audit methods for assessing tobacco marketing and products at the point of sale. Tob Control. 2014;23(2):98-106.

13. Henriksen L, Ribisl KM, Rogers T, et al. Standardized Tobacco Assessment for Retail Settings (STARS): dissemination and implementation research. Tob Control. 2016;25(Suppl 1):i67-i74.

14. Gong T, Lv J, Liu Q, et al. Audit of tobacco retail outlets in Hangzhou, China. Tob Control. 2013;22(4):245-249.

15. Hall MG, Kollath-Cattano C, Reynales-Shigematsu LM, Thrasher JF. Inter-rater reliability of measures to characterize the tobacco retail environment in Mexico. Salud Publica Mex. 2015;57(6):514-518.

16. Minami H, Tran LT, McCarthy DE. Using ecological measures of smoking trigger exposure to predict smoking cessation milestones. Psychol Addict Behav. 2015;29(1):122-128.

17. World Health Organization (WHO). Framework Convention on Tobacco Control. Geneva, Switzerland: WHO; 2003. Available at: http://apps.who.int/iris/ bitstream/10665/42811/1/9241591013.pdf. Áccessed March 2, 2018.

18. Tobacco and Primary Medical Services (Scotland) Act. Scottish Governement, 2010. Available at: http://www. legislation.gov.uk/asp/2010/3/pdfs/asp_20100003_ en.pdif. Accessed March 2, 2018.

19. Health (Tobacco, Nicotine etc. and Care) (Scotland) Bill. The Scottish Parliament, 2015. Available at: http://www. parliament.scot/parliamentarybusiness/Bills/89934.aspx Accessed March 2, 2018.

20. Rooke C, Cheeseman H, Dockrell M, et al. Tobacco point-of-sale displays in England: a snapshot survey of current practices. Tob Control. 2010;19(4):279-284.

21. Tobacco Advertising and Promotion Act. Department of Health, United Kingdom, 2002. Available at: http:// www.legislation.gov.uk/ukpga/2002/36/contents. Accessed March 2, 2018.

22. Stead M, Eadie D, MacKintosh AM, et al. Young people's exposure to point-of-sale tobacco products and promotions. Public Health. 2016;136:48-56.

23. Scottish Government. Ethnic Group Demographics. Available at: http://www.gov.scot/Topics/People/Equality/Equalities/DataGrid/Ethnicity/EthPopMig. Accessed January 18, 2018.

24. Scottish Index of Multiple Deprivation 2012: A National Statistics Publication for Scotland. Scottish Government, Edinburgh 2012. Available at: http://simd.scotland.gov. uk/publication-2012/. Accessed March 2, 2018.

25. Scottish Government Urban Rural Classification. Scottish Government, Edinburgh 2014. Available at: http:// www.gov.scot/Topics/Statistics/About/Methodology/UrbanRuraiClassification. Accessed March 2, 2018.

26. Cohen JE, Planinac L, Lavack A, et al. Changes in retail tobacco promotions in a cohort of stores before, during, and after a tobacco product display ban. Am J Public Health. 2011;101(10):1879-1881.

27. Henriksen L, Feighery EC, Schleicher NC, et al. Reaching youth at the point of sale: cigarette marketing is more prevalent in stores where adolescents shop frequently. Tob Control. 2004;13(3):315-318.

28. Wakefield MA, Terry-McElrath YM, Chaloupka FJ, et al. Tobacco industry marketing at point of purchase after the 1998 MSA billboard advertising ban. Am J Public Health. 2002;92(6):937-940.

29. US market monitor - 1 quarter 1999 update. Adenkule P, 1999. Available at: https://www.industrydocumentslibrary.ucsf.edu/tobacco/docs/ykwc0191. Accessed March 2, 2018.

30. Lavack AM, Toth G. Tobacco point-of-purchase promotion: examining tobacco industry documents. Tob Control. 2006;15(5):377-384.

31. Stemler SE, Tsai J. Best practices in estimating interrater reliability. In Osborne J, ed. Best Practices in Quantitative Methods. Thousand Oaks, CA: SAGE Publications; 2008:29-49.

32. McHugh ML. Interrater reliability: the kappa statistic. Biochemia Medica, 2012;22(3):276-282.

33. Guidance on the Definition of SIMD Quintiles. Dickie C, Edinburgh 2013. Available at: http://www.gov.scot/ Resource/0043/00439496.pdf. Accessed March 2, 2018.

34. Bogdanovica I, McNeill A, Britton J. Cohort study investigating the effects of first stage of the English tobacco point-of-sale display ban on awareness, susceptibility and smoking uptake among adolescents. BMJ Open. 2017;7(1). ???Page numbers???

35. Brose LS, Chong CB, Aspinall E, et al. Effects of standardised cigarette packaging on craving, motivation to stop and perceptions of cigarettes and packs. Psychol Health. 2014;29(7):849-860.

36. Seidenberg AB, Caughey RW, Rees VW, Connolly GN. Storefront cigarette advertising differs by community demographic profile. Am J Health Promot. 2010;24(6):e26e31.

37. Combs TB, Moreland-Russell S, Roche J. Evaluation of measurement tools for tobacco product displays: is there an app for that? AIMS Public Health. 2015;2(4):810-820.

38. Spanopoulos D, Ratschen E, McNeill A, et al. Retail price and point of sale display of tobacco in the UK: a descriptive study of small retailers. PLoS One. 2012;7(1):e29871. 


\section{APPENDIX A \\ Tobacco Visibility Measure}

\begin{tabular}{|c|c|}
\hline $\begin{array}{l}\text { Visibility } \\
\text { characteristics }\end{array}$ & $\begin{array}{l}\text { Characteristic rating } \\
(0-5)\end{array}$ \\
\hline Product visibility $^{\mathrm{a}}$ & $\begin{array}{l}4 \text { - Full visibility: all tobacco products on permanent display } \\
3 \text { - Some tobacco products on permanent display } \\
2 \text { - Some tobacco products on temporary display } \\
1 \text { - All tobacco products concealed within a public facing storage unit } \\
0 \text { - Zero visibility; all tobacco products stored out of sight }\end{array}$ \\
\hline \multicolumn{2}{|l|}{ Storage Unit Visibility } \\
\hline $\begin{array}{l}\text { 1. Visibility of tobacco } \\
\text { storage unit at the } \\
\text { point of purchase }\end{array}$ & $\begin{array}{l}\text { 5-All five proximity indicators } \\
\text { 4-Four proximity indicators } \\
\text { 3-Three proximity indicators } \\
\text { 2-Two proximity indicators } \\
\text { 1-One proximity indicator } \\
\text { 0-Zero proximity indicators }\end{array}$ \\
\hline $\begin{array}{l}\text { 2. Proximity of the } \\
\text { point of purchase sales } \\
\text { counter to customer } \\
\text { traffic }\end{array}$ & $\begin{array}{l}\text { 5-Purchased from the store's main sales counter } \\
\text { 4-Purchased from a separate sales counter with high passing traffic flow } \\
\text { 3-Purchased from a separate sales counter with moderate passing traffic flow } \\
\text { 2-Purchased from a separate sales counter with low passing traffic flow and high counter visibility } \\
\text { 1-Purchased from a separate sales counter with low passing traffic flow and low counter visibility }\end{array}$ \\
\hline $\begin{array}{l}\text { 3. Size of storage unit } \\
\text { (sqm) }\end{array}$ & $\begin{array}{l}5-2.800 \mathrm{sqm}+ \\
4-2.300 \mathrm{sqm}-2.799 \mathrm{sqm} \\
3-1.800 \mathrm{sqm}-2.299 \mathrm{sqm} \\
2-1.300 \mathrm{sqm}-1.799 \mathrm{sqm} \\
1-0.001 \mathrm{sqm}-1.299 \mathrm{sqm} \\
0-\text { No visible storage unit }\end{array}$ \\
\hline $\begin{array}{l}\text { 4. In-store observer } \\
\text { conspicuousness score } \\
\text { for storage unit }\end{array}$ & $\begin{array}{l}5 \text { 'High' to } 1 \text { 'Low' } \\
\text { 0-No visibility }\end{array}$ \\
\hline $\begin{array}{l}\text { 5. External visibility of } \\
\text { storage unit }\end{array}$ & $\begin{array}{l}\text { 2-Both positions }{ }^{\mathrm{d}} \\
\text { 1-One position } \\
\text { 0- Neither position }\end{array}$ \\
\hline
\end{tabular}

Note.

To compute storage unit visibility add together the individual scores for the in-store and external visibility measures (range 1-22).

a: Relates to products containing tobacco (eg, FMCs, RYOs, Cigars) and does not include smoking accessories (eg, filters, cigarette papers)

b: Storage unit visibility indicators: behind the service counter; at customer eye-level; within arms-reach of the shop assistant; parallel to the counter; availability of tobacco clearly denoted by generic signage / active display

c: High traffic = customers pass the front of the sales counter when entering AND leaving store; Moderate traffic $=$ customers pass the front of the sales counter when either entering OR leaving the store; Low traffic $=$ customers DO NOT pass then front of the sales counter when entering and leaving the store; High counter visibility = tobacco counter is in direct line of sight of HALF OR MORE of the service till points; Low counter visibility = tobacco counter is in direct line of sight of LESS THAN HALF of the service till points.

d: External visibility positions: storage unit visible from the pedestrian footway; storage unit visible from the main entrance 


\section{APPENDIX B \\ Display Visibility Measures}

$\underline{\text { Visibility }}$

Q. Is the storage (display) unit positioned behind the counter area? (i.e. out with customer reach)

$\square$ Yes

$\square$ No

$\square$ Tobacco store is out of sight (e.g. drawer under the counter)

Q. Is the storage (display) unit positioned at customer eye level? (i.e. all or part of unit is above the counter)

$\square$ Yes

$\square$ No

$\square$ Tobacco store is out of sight (e.g. drawer under the counter)

Q. Is the storage (display) unit within arms-reach of shop assistant serving the customer? (i.e. no more than two steps distance from the (nearest) till-point)

$\square$ Yes

$\square$ No

$\square$ Tobacco store is out of sight (e.g. drawer under the counter)

Q. Is the storage (display) unit positioned parallel to the counter? (i.e. out with customer reach)

$\square$ Yes

$\square$ No

$\square$ Tobacco store is out of sight (e.g. drawer under the counter)

Q. Is there any generic signage on the tobacco storage (display) unit designed to indicate that tobacco products are on sale?

$\square$ Yes (describe):

No

Q. From what sales counter are tobacco products purchased from?

$\square$ The main sales counter where most other goods are purchased

$\square$ A separate tobacco counter or kiosk

Q. If customers purchase tobacco from a separate counter, where is it positioned? Indicate using one of the following in descending order:

$\square$ Customers pass in front of the counter when entering and leaving the store OR

$\square$ Customers pass in front of the counter either when entering or leaving the store OR

$\square$ The counter is in direct line of sight of half or more of the shops service tills OR

$\square$ The counter is in direct line of sight of less than half of the shops service tills

Q. How large is the storage (display) unit?

Height: no. of rows / shelves:

Width: no. of columns:

Not applicable / no storage unit 
Q. How conspicuous is the storage (display) unit?

Assess visibility of display/storage unit taking into account its ability to standout within the shop setting as the customer approaches the sales counter.

$$
\text { Low visibility }
$$

1
2

0 Not visible

3

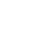

Q. Is the tobacco storage (display) unit visible from outside the store (i.e. from footway)?

$\square$ Yes

No

Tobacco store is out of sight (e.g. drawer under the counter)

Q. Is the tobacco storage (display) unit visible from the store's main entrance (i.e. as you are about to cross the threshold)?

$\square$ Yes

No

Tobacco store is out of sight (e.g. drawer under the counter)

\section{Compliance}

Q. How effective is the storage unit design and cover mechanism at concealing products from public view? (i.e. including state of repair and excluding any impact of poor server practice)

$\square$ Effective

Partially effective (explain):

Ineffective (explain):

NA (no public facing storage unit noted)

Q. Are any of the following tobacco and smoking- related products on permanent display within the store in direct contravention to the ban? Permanent displays refers to both purpose designed and standard shelf displays

$\square$ Cigarettes

Cigarette filters

Cigarette papers

Devices for making cigarettes

Smoking pipes

Loose tobacco

Cigars

Other smoking products covered (describe):

None noted

Q. IF ON PERMANENT DISPLAY: Where within the store were the offending products on display? (including displays within or products visible immediately behind the shop window) 
Q. Taking into account legitimate exemptions (legitimate actions include the temporary display of products necessary to fulfil a customer request to view a product or to retrieve a product for sale. Or for stocktaking, restocking, pricing, staff training and the cleaning, refurbishing and refitting of storage units) were any tobacco or smoking related products left on temporary display by shop staff for longer than was necessary to undertake a sale or any other legitimate action? (e.g. covers left open, stock left on open display awaiting storage)

$\square$ Yes

$\square$ Possibly

$\square$ No

Q. IF YES or POSSIBLY: What was the nature of the contravention?

(describe):

Assessed compliance score range 0 to 4 (Write in): 


\begin{tabular}{|c|c|c|c|}
\hline \multicolumn{4}{|c|}{$\begin{array}{c}\text { APPENDIX C } \\
\text { DISPLAY Visibility Tool Inter-rater Reliability }\end{array}$} \\
\hline Characteristic & Measure item & $\begin{array}{c}\text { Level of } \\
\text { agreement (\%) }\end{array}$ & $\begin{array}{c}\text { Cohen's } \\
\text { Kappa (k) }\end{array}$ \\
\hline \multirow{5}{*}{$\begin{array}{l}\text { Visibility from sales } \\
\text { counter }\end{array}$} & Behind sales counter $(\mathrm{Y} / \mathrm{N})$ & 100 & 1.00 \\
\hline & At eye-level $(\mathrm{Y} / \mathrm{N})$ & 100 & 1.00 \\
\hline & Within arms-reach $(\mathrm{Y} / \mathrm{N})$ & 100 & 1.00 \\
\hline & Parallel to sales counter $(\mathrm{Y} / \mathrm{N})$ & 100 & 1.00 \\
\hline & Generic signage/permanent display $(\mathrm{Y} / \mathrm{N})$ & 92 & 0.76 \\
\hline Proximity to routine traffic & Scale $1-5$ & 100 & 1.00 \\
\hline \multirow[t]{2}{*}{ Display area } & Height: no. rows & 92 & 0.90 \\
\hline & Width: no. columns & 100 & 1.00 \\
\hline Display conspicuousness & Scale $1-5$ & 92 & 0.80 \\
\hline \multirow[t]{2}{*}{ External visibility } & Internal display visible from footway $(\mathrm{Y} / \mathrm{N})$ & 100 & 1.00 \\
\hline & Internal display visible from entrance $(\mathrm{Y} / \mathrm{N})$ & 100 & 1.00 \\
\hline Product visibility & Scale $0-4$ & 92 & 0.87 \\
\hline
\end{tabular}

\section{APPENDIX D \\ Supplementary Figure}

The graph below shows the change in tobacco storage visibility over time by store type. It can be seen from the graph that there is some decline in mean storage visibility for most outlet types but that the error bars for the standard error of the mean are over lapping.

\section{Change in Tobacco Storage Visibility Over Time by Store Type}

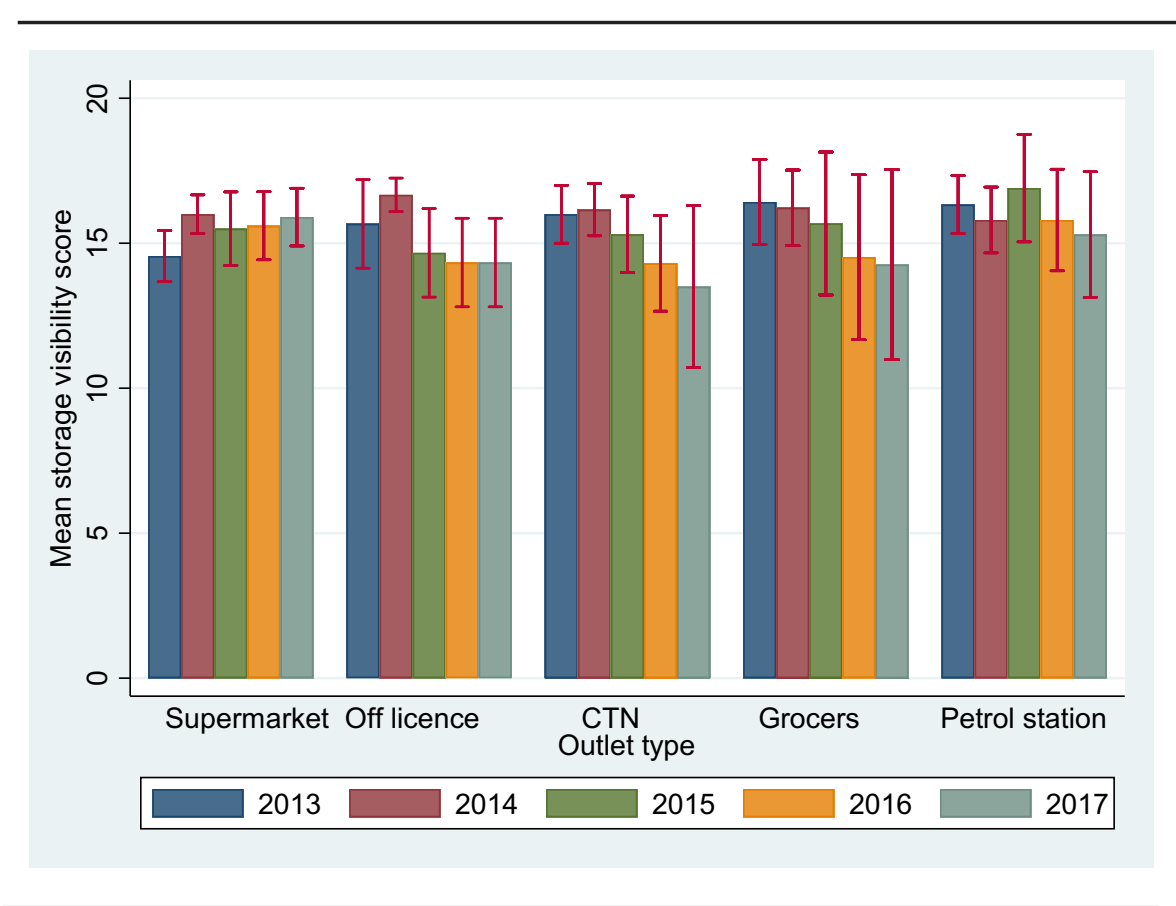

Note.

Standard error of the mean is Indicated by capped lines. 